\title{
Review
}

\section{Granzymes in age-related cardiovascular and pulmonary diseases}

\author{
A Hendel ${ }^{1}$, PR Hiebert ${ }^{1}$, WA Boivin ${ }^{1}$, SJ Williams ${ }^{1}$ and DJ Granville ${ }^{*, 1}$
}

Chronic inflammation is a hallmark of age-related cardiovascular and pulmonary diseases. Granzymes are a family of serine proteases that have been traditionally viewed as initiators of immune-mediated cell death. However, recent findings suggest that the pathophysiological role of granzymes is complex. Emerging functions for granzymes in extracellular matrix degradation, autoimmunity, and inflammation suggests a multifactorial mechanism by which these enzymes are capable of mediating tissue damage. Recent discoveries showing that granzymes can be produced and secreted by nonimmune cells during disease provide an additional layer of intricacy. This review examines the emerging biochemical and clinical evidence pertaining to intracellular and/or extracellular granzymes in the pathogenesis of aging and cardiopulmonary diseases.

Cell Death and Differentiation (2010) 17, 596-606; doi:10.1038/cdd.2010.5; published online 5 February 2010

Inflammation is the fundamental process by which the body responds to injurious stimuli and initiates healing of damaged tissue. Although the beneficial role of inflammation is to defend the host and to ensure host survival, unresolved inflammation in the face of continuous stimuli promotes a chronic inflammatory response that underpins many agerelated disorders. ${ }^{1}$ This has given rise to the molecular inflammation hypothesis of aging, which postulates that lowgrade inflammatory processes converging with physiological changes during aging yield the underlying pathogenesis of many age-related diseases. ${ }^{2}$

Oxidative stress exacerbates inflammation during aging. ${ }^{3}$ Alterations in redox balance and increased oxidative stress during aging precipitate the expression of cytokines such as TNF- $\alpha$, interleukins (IL-1 $\beta$, IL-2, and IL-6), chemokines, and adhesion molecules (intercellular adhesion molecule-1, ICAM-1; vascular cell adhesion molecule-1, VCAM-1; E-selectin), and other enzymes (e.g., iNOS and cyclooxygenase-2 (COX-2)). ${ }^{2}$ Constitutive activation and recruitment of macrophages, $T$ cells, and mast cells foster the release of proteases leading to extracellular matrix (ECM) degradation, cell death, remodeling, and other events that ultimately result in tissue and organ damage during chronic inflammation. ${ }^{4-6}$ Although our understanding of inflammatory mediators in aging is increasing, the role of specific effector molecules that augment tissue damage in age-related disorders remains poorly understood. Attempts to control the progression of chronic inflammatory diseases by modulating key mediators of inflammation may be detrimental in an elderly population that is prone to immunodeficiency. ${ }^{6,7}$ As such, preferred strategies for limiting inflammation in chronic illness may involve the targeting of effector molecules such as proteases.

A family of proteases that has been reported to be evident in a variety of age-related chronic inflammatory diseases are granzymes. There are five human granzymes with a range of substrate specificities: granzyme A (GrA-tryptase), granzyme B (GrB-aspase), granzyme H (GrH-chymase), granzyme K (GrK-tryptase), and granzyme M (GrM-metase). GrA and GrB are the most abundant and most studied granzymes and have been predominantly thought to be involved in immunemediated killing of transformed, allogeneic, and/or, virally infected cells through a mechanism involving the membraneperforating molecule, perforin, that facilitates granzyme entry into the target cell leading to induction of cell death. ${ }^{8} \mathrm{GrB}$ induces apoptosis through caspase-dependent and -independent pathways (reviewed in Boivin et $a l^{9}$ ). GrA was originally thought to induce caspase-independent cell death, however, recent findings indicate that GrA may be involved in immune regulation through the induction of cytokine release. $^{10,11}$ Mechanisms leading to cell death by other granzymes $(H, K$, and $M)$, often referred to as orphan granyzmes due to their ill-defined roles in cell killing, have shown both caspase-dependent and/or caspase-independent pathways leading to cell death. ${ }^{10}$

Although the specific role of GrB in cytotoxic T lymphocyte (CTL)-mediated killing of transformed and viral infected cells is well described, much less is known about the broader roles of granzymes in chronic diseases. Emerging evidence

\footnotetext{
${ }^{1}$ Department of Pathology and Laboratory Medicine, Providence Heart + Lung Institute, St. Paul's Hospital, University of British Columbia, Vancouver, British Columbia, Canada

*Corresponding author: DJ Granville, Department of Pathology and Laboratory Medicine, Providence Heart + Lung Institute, St. Paul's Hospital, University of British Columbia, Room 166, Burrard Building, 1081 Burrard Street, Vancouver, British Columbia V6Z 1Y6, Canada. Tel: + 6048069267 ; Fax: + 604 806 9274;

E-mail: David.Granville@hli.ubc.ca

Keywords: granzymes; inflammation; COPD; aging; aneurysm; extracellular matrix

Abbreviations: ICAM-1, intercellular adhesion molecule-1; VCAM-1, vascular cell adhesion molecule-1; COX-2, cyclooxygenase-2; ECM, extracellular matrix; CTL, cytotoxic T lymphocyte; SMC, smooth muscle cell; Gr, granzyme; COPD, chronic obstructive pulmonary disease; AAA, abdominal aortic aneurysm

Received 07.9.09; revised 18.12.09; accepted 21.12.09; Edited by G Salvesen; published online 05.2.10
} 
suggests an extracellular role for granzymes during inflammation, and several reports indicate that granzymes are expressed and secreted by noncytotoxic cells during disease. However, most investigations thus far linking granzyme activity to disease have been separated into two camps whereby one has traditionally viewed granzyme expression and/or increased protein in extracellular/bodily fluids (e.g., plasma, synovial fluid, cerebral spinal fluid) as markers of cytotoxic lymphocyte activity in the clinic whereas the other has used in vitro biochemical/cell culture studies to elucidate the mechanisms by which granzymes function. However, mechanistic animal studies that connect clinical observations with in vitro data are sorely lacking. This review evaluates current evidence regarding the mechanism and role of granzymes in inflammatory diseases with a focus on cardiovascular and pulmonary diseases.

\section{Granzyme-Induced Apoptosis in Disease}

Immune-mediated apoptosis promotes local tissue damage during the inflammatory response. ${ }^{1}$ Elevated levels of proinflammatory cytokines promote immune cell infiltration and activation, which, in turn, promotes increased granzyme production in the inflamed tissue. ${ }^{8}$ For this reason, immunemediated, granzyme-induced apoptosis may have a causative role in the pathogenesis of chronic inflammatory diseases.

Chronic obstructive pulmonary disease (COPD) is an agerelated disease that is characterized by small airway destruction and emphysema due to the destruction of alveolar parenchymal tissue and increased death of lung epithelial, endothelial, and interstitial mesenchymal cells. Hallmarks of
COPD and emphysema include inflammation, alveolar epithelial cell apoptosis, and proteolytic ECM degradation. ${ }^{12,13}$ Epithelial cell apoptosis is considered an early event in COPD pathogenesis. ${ }^{6}$ Increased GrB and perforin expressing CD8 + and CD3 + cells are found in the bronchoalveolar lavage (BAL) and blood of COPD patients. ${ }^{14}$ Furthermore, GrB-positive $T$ cells are positively correlated with bronchial epithelial cell apoptosis in the BAL of COPD patients. ${ }^{14}$ Immunohistological studies of COPD lung tissue localized GrB-positive CTL and GrA-positive NK cells in bronchial and alveolar walls. $^{15}$ Interestingly, $\mathrm{GrA}$ and $\mathrm{GrB}$ were also identified in alveolar macrophages and in type II pneumocytes of control and COPD patients (Table 1). However, no significant differences in GrA- and GrB-positive immune cells were found between COPD patients and the control group, whereas GrA staining in type II pneumocytes was significantly greater in COPD patients when quantified using immunolabeling but not by mRNA levels. ${ }^{15}$ The lack of a significant difference in granzyme expression was explained by the fact that the morphologically 'normal' tissues used as controls were obtained from lung cancer patients in which elevated GrA and GrB would be expected. ${ }^{15}$ Unfortunately perforin expression was not assessed in this study so it is unclear as to whether type II pneumocytes that express granzymes are capable of inducing granzyme/perforin-induced cell death.

Although there is evidence for GrA and GrB expression by immune and nonimmune cells in COPD, it is yet to be determined whether granzyme-induced apoptosis has a causative role in the progression of this disease (Figure 1). In this regard, animal studies are severely lacking. As there are no ideal mouse models of COPD, an alternative approach would be to assess granzyme function using smoking-induced

Table 1 Granzyme expression and method of detection in noncytotoxic cells

\begin{tabular}{|c|c|c|c|}
\hline Cell type & Species and source & Evidence & Reference \\
\hline \multicolumn{4}{|l|}{ Granzyme A } \\
\hline Type II pneumocytes & Human tissue & mRNA (PCR, laser capture) and protein (IHC) & 15 \\
\hline Alveolar macrophages & Human tissue & mRNA and protein (PCR, laser capture, and IHC) & 15 \\
\hline Bronchiolar epithelial cells & Human tissue & mRNA and protein (PCR, laser capture, and IHC) & 15 \\
\hline \multicolumn{4}{|l|}{ Granzyme B } \\
\hline Vascular SMC & Human tissue & Protein (IHC, WB) & 16 \\
\hline \multirow[t]{2}{*}{ Keratinocytes } & Human cells & mRNA (PCR) and protein (confocal IHC, WB) & 17 \\
\hline & Human tissue and cells & mRNA, (PCR), and protein (IHC) & 18 \\
\hline Syncytial trophoblasts & Human tissue and cells & mRNA (PCR) and protein (IHC) & 19 \\
\hline Spermatozoa & Human tissue & mRNA (ISH, PCR) and protein (IHC) & 19 \\
\hline Mast cells & Human cells & mRNA (PCR), protein (confocal IHC, ELISA), and activity (ELISA) & 20 \\
\hline Granulosa cells & Human cells & Protein (confocal IHC, WB) & 21 \\
\hline B cells & Human cells & Protein (IF, WB, FACS), mRNA (RT-PCR), and activity (ELISA) & 22 \\
\hline Basophils & Human cells & mRNA (PCR) and protein (WB, ELISA) & 23 \\
\hline Plasmacytoid dendritic cells & Human cells & mRNA (PCR) and protein & 24 \\
\hline Chondrocytes & Human tissue & mRNA (ISH, PCR) and protein (IHC) & 25 \\
\hline Carcinoma (breast) & Human tissue and cells & mRNA (RPA and northern) and protein (IHC) & 26 \\
\hline Type II pneumocytes & Human tissue & mRNA (PCR, laser capture) and protein (IHC) & 15 \\
\hline \multirow[t]{2}{*}{ Regulatory $\mathrm{T}$ cells } & Mouse cells & mRNA (microarray, PCR) and protein (FACS) & 27 \\
\hline & Human cells & Protein (FACS) & 28 \\
\hline \multirow[t]{2}{*}{ Macrophages } & Human tissue and cells & mRNA (PCR, ISH) and protein (FACS, IHC) & 29 \\
\hline & Human tissue & Protein (IHC) & 16 \\
\hline Alveolar macrophages & Human tissue & mRNA (PCR, laser capture) and protein (IHC) & 15 \\
\hline
\end{tabular}

WB, western blot, IHC, immunohistochemistry; ISH, in situ hybridization; IF, immunofluorescence; FACS, fluorescence-activated cell sorting; RPA, ribonuclease protection assay; ELISA, enzyme-linked immunosorbent assay; SMC, smooth muscle cell; RT-PCR, reverse transcription-PCR. Emerging evidence that granzymes are expressed in multiple immune and nonimmune cell types in addition to $\mathrm{CTL}$ and NK cells. Expression patterns for granzymes $\mathrm{H}$, $\mathrm{K}$, and $\mathrm{M}$ in normal and disease environments are poorly understood. 


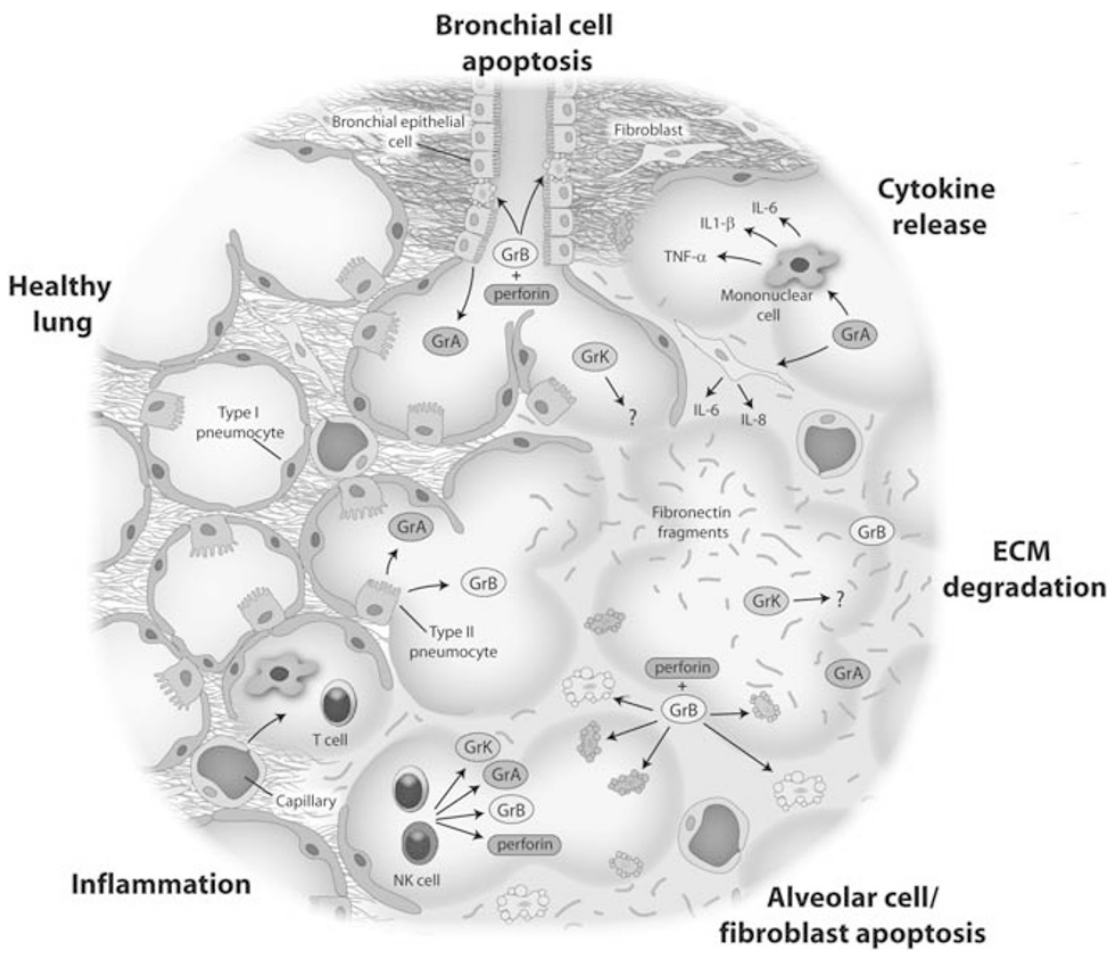

Figure 1 Putative mechanism of action for granzymes in inflammatory lung pathologies. Levels of soluble GrA, GrB, and GrK as well as granzyme-positive CTL and NK cells are increased in BAL of COPD (GrA and GrB only), bronchopneumonia, and in allergic asthma patients. Bronchial epithelial cells express GrA whereas type II pneumocytes in the lung parenchyma express GrA and GrB. Extracellular GrA and GrB may degrade ECM proteins leading to increased soluble fibronectin fragments and an overall loss of ECM in the alveolar wall. Granzyme-mediated fibroblast apoptosis results in decreased ECM production contributing to disruption of the lung parenchyma. GrBmediated apoptosis of type I and II pneumocytes as well as bronchial epithelial cells is also observed. Extracellular GrA in the lung can induce lung fibroblasts to express IL-6 and IL-8 while inducing IL1- $\beta$, TNF- $\alpha$, and IL-6 in mononuclear cells resulting in an increased immune response, further amplifying granzyme levels and activity

emphysema rodent models and incorporating both granzyme knockout $(\mathrm{KO})$ and perforin-KO mice. In support of the latter model, increased GrB-positive CD3 + and CD8 + cells were detected in the BAL and blood of COPD patients (smokers and ex-smokers) in comparison to asymptomatic controls (smokers and non-smokers). ${ }^{14}$ Thus, using smoking-induced animal models may help clarify the role of granzymes in this disease.

Atherosclerosis is a disease that progresses over decades and is characterized by endothelial dysfunction, excessive lipid deposition, chronic inflammation, cell death, altered ECM synthesis and degradation, and vascular remodeling. ${ }^{30}$ Prolonged inflammation results in reduced plaque cellularity and ECM degradation leading to the formation of an unstable, rupture-prone plaque. Atherosclerotic plaque rupture and thrombosis are the primary causes of heart attack, stroke, and lower limb loss in diabetic patients. In atherosclerosis, granzyme-induced apoptosis may contribute to plaque instability by promoting cell death within the plaque and increasing the risk of rupture by promoting smooth muscle cell (SMC) and macrophage foam cell apoptosis in the fibrous cap. ${ }^{31}$ Reduced nitric oxide (NO) bioavailability is a hallmark of endothelial dysfunction in the earlier stages of atherosclerosis. ${ }^{32}$ Interestingly, NO inhibits GrA, GrB, and perforin release from activated killer cells. ${ }^{33}$ As such, it is conceivable that reduced NO could foster the release of granular content from infiltrating CTLs, potentially contributing to apoptosis within the plaque. As endothelial superoxide generation increases with age, elevated superoxide-mediated NO scavenging and subsequent peroxynitrite formation would be expected to facilitate the release and accumulation of granzymes in the atheroma. Indeed, although $\mathrm{GrB}$ is absent from healthy vessels, immunohistological studies of human coronary arteries with mild and advanced atherosclerotic lesions exhibit increased GrB expression in CTLs, macrophage foam cells, and SMCs in advanced lesions. ${ }^{16}$ Colocalization of GrB and TUNEL-positive intimal SMCs and macrophage foam cells suggests that GrB may be inducing apoptosis in these cells. ${ }^{16}$ Interestingly, the GrB endogenous inhibitor, proteinase inhibitor 9 , is reduced in unstable compared to stable lesions, ${ }^{34}$ suggesting on a potential imbalance between $\mathrm{GrB}$ and its endogenous inhibitor during atherogenesis. Further in vitro experiments on cultured human coronary artery SMCs and endothelial cells illustrated that co-administration of purified GrB with either adenovirus (Ad5) and/or perforin induced apoptosis, suggesting that vascular cells are susceptible to GrB-induced apoptosis. ${ }^{35,36}$

Several clinical studies showed a correlation between GrB expression and increased atherosclerotic lesion severity. Peripheral blood mononuclear cells (PBMC) isolated from patients with unstable angina, reflective of increased plaque vulnerability, produce and release higher levels of $\mathrm{GrB}$ than PBMC isolated from patients with stable angina ${ }^{37}$ Conditioned media of PBMC from patients with unstable angina induced apoptosis in cultured endothelial cells, suggesting that the high expression of GrB by PBMC within this group may be inducing 
apoptosis in unstable angina patients. However, no information was provided regarding the activity or concentration of $\mathrm{GrB}$ and perforin in the conditioned media used. As GrB has been implicated in promoting cell detachment and anoikis through cleavage of ECM proteins (discussed below), one cannot differentiate between the intracellular or the extracellular activity of GrB using these methods.

Elevated GrB plasma levels were detected in patients after acute myocardial infarction ${ }^{38}$ and in patients with unstable carotid plaques, which correlated to increased cerebrovascular events. ${ }^{39}$ However, a causative role for granzymes in atherosclerosis and plaque rupture requires further study as increased GrB in the plasma may, as discussed below, represent a potential extracellular role for this protease in disease. ${ }^{9}$ For that reason, studies that use granzyme and/or perforin-KO animal models of atherosclerosis will significantly clarify the intracellular and/or extracellular role of granzymes in promoting atherosclerotic plaque instability. In this regard, Schiller et al..$^{40}$ examined the role of perforin in atherosclerotic plaque development using the proatherogenic LDL receptor knockout mice model (LDLr-KO). As no difference in plaque size was observed between LDLr-KO mice and perforin double-knockout mice (LDLr/perforin-DKO), it was concluded that atherosclerosis does not involve the granzyme/perforin cytolytic pathway. However, the effect of perforin-independent, extracellular granzyme activity cannot be ruled out in the latter study as the use of perforin-deficient mice alone would not rule out such a role for granzymes.

As shown in Table 1, increasing evidence suggests that there are multiple cellular sources for granzymes, from both immune and nonimmune cell types, during disease. Whether granzyme expression in noncytotoxic cells equip them with cytotoxic capabilities is still questionable as it is unclear if these cells can express perforin and form an immunological synapse that will allow sufficient granzyme delivery to a target cell. Collectively, much research is required in this area to differentiate granzyme expression in various cell types and disease and to ascertain how and what provoke granzyme expression in cell types that do not express granzymes under so-called 'resting' or 'normal' conditions. In addition, further confirmation for granzyme expression in these cells must extend beyond antibody detection alone to include techniques such as laser capture microdissection, mRNA analysis, mass spectrometry, and/or ex vivo derived cells from granzymespecific $\mathrm{KO}$ animals to further verify granzyme expression. Further research must also be carried out into the expression patterns of the other granzymes $(\mathrm{A}, \mathrm{H}, \mathrm{K}, \mathrm{M})$ in healthy versus diseased tissues.

\section{Extracellular Granzymes in Chronic Inflammation}

Extracellular matrix degradation and remodeling characterize age-associated tissue degeneration. Recent years have seen an accrual of evidence highlighting the diverse extracellular activities of granzymes as attention to this area continues to expand. Granzymes were originally proposed to exert their effect in the extracellular environment over two decades ago when it was suggested that a proportion may escape from the immunological synapse during CTL degranulation. ${ }^{41}$ Several years later Isaaz et al. ${ }^{42}$ reported that up to a third of GrA and
GrB may be constitutively secreted by $\mathrm{T}$ cells following activation by a granule-independent mechanism. This work was expanded on by Prakash et al., ${ }^{43}$ who showed that both active and zymogen forms of GrB can be released constitutively, with NK cells primarily releasing the active form through the typical granule pathway and CTLs secreting the inactive zymogen in a granule-independent manner. Furthermore, reports have documented extracellular granzyme release by lymphocytes in response to cytokine/chemokine stimuli ${ }^{44}$ whereas additional evidence suggests integrin interactions with ECM proteins such as fibronectin and vitronectin may contribute to T-cell activation and extracellular granzyme release. ${ }^{45-48}$

Although direct evidence of granzyme-mediated cleavage of extracellular substrates under physiological conditions is limited, the discovery of a number of extracellular substrates in vitro has formed the basis for hypotheses linking extracellular granzyme activity to disease pathogenesis (Table 2). ${ }^{9}$ GrA cleaves fibronectin, myelin basic protein, and basement membrane proteoglycans in vitro. ${ }^{53,57,67}$ Evidence of GrA disrupting basement membrane proteins and thereby facilitating lymphocyte migration was proposed by Simon et al., ${ }^{55}$ who showed in vitro that high GrA concentrations $(50 \mu \mathrm{g} / \mathrm{ml})$ could cleave the $\alpha 2$ (IV) chain of collagen IV. However, more work is needed to establish the in vivo relevance of these findings. GrA may also function extracellularly as a proinflammatory mediator by stimulating cytokine release in a number of different cell types (discussed in detail below).

The intracellular role of GrB in cytotoxicity remains a critical function of this enzyme. However, the discovery of extracellular GrB substrates has prompted researchers to revisit its role in disease. Cleavage of the prohemostatic molecule, von Willebrand factor, by GrB was shown to delay platelet aggregation, suggesting that GrB may have antithrombotic properties. $^{62}$ In vitro experiments have also shown the ability of GrB to cleave several components of the ECM including fibronectin, vitronectin, laminin, and fibrillin-1, suggesting a causative role for GrB in inducing cell detachment and promoting further damage to the ECM. ${ }^{35,58,60,61}$ In particular, GrB cleavage of aggrecan, a cartilage proteoglycan degraded in RA, has led to several studies investigating the pathological role of $\mathrm{GrB}$ in this disease ${ }^{58}$ Ronday et al. ${ }^{59}$ showed that GrB mediated the degradation of proteoglycans, but not collagen, in matrix synthesized by cultured chondrocytes. Proteoglycans from bovine articular cartilage explants were also cleaved by GrB. However, an important caveat in such in vitro studies is that the granzyme concentrations used may be higher than that found in vivo. Indeed, although localized inflammation would result in elevated granzyme concentrations in proximity to the ECM, the in vivo relevance of these observations remains to be validated in animal models.

GrB-mediated ECM cleavage may also affect cellular motility as purified GrB inhibited tumor cell migration in vitro. ${ }^{61}$ Purified GrB from UV-exposed keratinocytes also inhibited migration of keratinocytes cultured on a fibronectin matrix, suggesting a role for GrB in attenuating skin wound healing and/or carcinogenesis. ${ }^{18}$ ECM cleavage by GrB also induces cell detachment and anoikis of endothelial and vascular SMC suggesting a perforin-independent mechanism for GrBinduced cell death. ${ }^{35,61}$ 
Table 2 Extracellular granzyme substrates and potential pathophysiological consequences

\begin{tabular}{ll} 
Substrates & $\begin{array}{l}\text { Potential physiological relevance/patholog } \\
\text { significance }\end{array}$ \\
\hline $\begin{array}{l}\text { Granzyme } A \\
\begin{array}{l}\text { Proteinase- } \\
\text { activated } \\
\text { receptor-2 (PAR-2) }\end{array}\end{array}$ & $\begin{array}{l}\text { May contribute to inflammation and pathogene } \\
\text { infectious colitis. Yields PAR-2-activating peptide } \\
\text { SLIGRL. }\end{array}$ \\
$\begin{array}{l}\text { Thrombin } \\
\text { receptor }\end{array}$ & $\begin{array}{l}\text { Neuronal cells - cleavage results in reversed } \\
\text { stellation in astrocytes and neurite retraction, } \\
\text { implications in allergic encephalomyelitis. } \\
\text { Platelets - GrA binding attenuates thrombin- } \\
\text { dependent platelet aggregation. }\end{array}$
\end{tabular}

Fibronectin

Collagen IV

Pro-urokinase plasminogen activator (pro-uPA) Myelin basic protein (MBP)

\section{Granzyme B} Aggrecan

Cartilage proteoglycans

Fibrillin-1

Laminin

Vitronectin

Fibronectin

von Willebrand factor (VWF)

Fibrinogen
May influence lymphocyte migration, cell adhesion, and/or anoikis. Cleavage induces epithelial cell detachment and reduced epithelial cell-basement membrane interactions. Implications in immune cellmediated tumor cell death.

$T$ cells bind to basement membranes and GrA cleaves collagen IV, predominantly the $\alpha$-2(IV) chain. Results in destabilization of the basement membrane and could affect migration. Cleavage results in reduced epithelial cell-basement membrane interactions. Implications in tumor cell anoikis.

Converts pro-uPA into active UPA - implications in plasmin generation and lymphocyte migration through clots.

Degradation could contribute to myelin destruction and multiple sclerosis.

GrB levels are elevated in synovial fluid in rheumatoid arthritis. Aggrecan is a major constituent of cartilage. Cleavage would reduce the structural integrity of cartilage.

Reduced structural integrity of cartilage, cleavage may contribute to rheumatoid arthritis.

Cleavage leads to reduced elastic fiber strength, disorganization, and medial disruption. In vitro and in vivo evidence for GrB cleavage of fibrillin-1 and role in aneurysm progression and rupture in vivo. First study to show a perforin-independent, extracellular proteolytic role for $\mathrm{GrB}$ in an in vivo model of disease.

Implications in cell adhesion, anoikis, and migration.

Cleavage in the RGD integrin-binding domain. Implications in cell adhesion, migration and anoikis. Implications for cell adhesion, migration, and anoikis.

Cleavage site in platelet interaction domain may prevent/delay thrombosis. Cleavage site identified:
Asp $^{709}$, Glu

Antithrombosis implications as fibrinogen is responsible for platelet adhesion and thrombus growth. Cleavage site identified: Asp ${ }^{230}$.
Comments

Reference

$194 \mathrm{nM}$ recombinant murine GrA converted $22 \%$ of peptide containing residues $30-45$ of rat PAR-2 to activated PAR-2 peptide. $20 \mathrm{~h}$ reaction time. Cleavage confirmed by mass spectrometry. Mouse GrA cleaved $\mathrm{N}$ terminus of the human thrombin receptor (amino acids 38-60). Catalytic rate for GrA cleavage is $2 \times 10^{4} \mathrm{M}^{-1} \mathrm{~s}^{-1}$ compared with thrombin catalytic rate of $8 \times 10^{7} \mathrm{M}^{-1} \mathrm{~s}^{-1}$. Purified murine GrA cleaved 32-mer peptide corresponding to amino-acid residues $29-60$ of the human receptor extracellular $\mathrm{N}$-terminal region in the same site as thrombin. ${ }^{51}$ Neurite retraction with GrA had $\mathrm{EC}_{50}=1 \mathrm{nM}$, compared to $50 \mathrm{pM}$ for thrombin. ${ }^{51} 100 \mathrm{nM}$ GrA blocked thrombin (1 nM)dependent platelet aggregation. ${ }^{52}$

20-100 units of purified murine GrA cleaved purified human plasma fibronectin into multiple fragments after 1.5-2 h. ${ }^{53} 300 \mathrm{nM}$ recombinant GrA increased epithelial cell detachment from fibronectin-coated plates after $24 \mathrm{~h}^{.54}$

$300 \mathrm{nM}$ recombinant GrA increased epithelial cell detachment from collagen IV-coated plates after 24 h. $^{54}$

Purified murine GrA was used at $50 \mu \mathrm{g} / \mathrm{ml}$ cleaved human collagen IV after $2 \mathrm{~h} .^{55}$

Purified human GrA was used at $1.7 \mathrm{nM}$ to cleave recombinant pro-uPA after $24 \mathrm{~h}$. Activation of prouPA by GrA was functionally equivalent to activation by $0.7 \mathrm{nM}$ of plasmin.

Purified granule extracts from rat NK cell line hydrolyzed human MBP. Incubation of granule extracts with anti-GrA antibody reduced MBP hydrolysis. Further confirmation using purified GrA and substrate is required.

Purified human GrB cleaved aggrecan monomers purified from rat chondrosarcoma cell line with a catalytic rate of $1.7 \times 10^{7} \mathrm{M}^{-1} \mathrm{~s}^{-1}$, which is 425 -fold faster than stromelysin-1 and 3200 -fold faster than GrA.

$0.4 \mu \mathrm{g} / \mathrm{ml}$ purified human GrB degraded matrix synthesized by bovine chondrocytes in $24 \mathrm{~h}$. 0.04 and $0.4 \mu \mathrm{g} / \mathrm{ml} \mathrm{GrB}$ degraded bovine articular cartilage explants after $90 \mathrm{~h}$ exposure.

In vitro - $80 \mathrm{nM}$ purified human $\mathrm{GrB}$ cleaved human fibrillin-1 from ECM synthesized by human coronary artery SMC in $24 \mathrm{~h}$. In vivo - fibrillin-1 cleavage fragments in serum of angiotensin-treated apoE-KO mice were absent in apoE-KO mice that were deficient in GrB.

50 and $100 \mathrm{nM}$ purified and recombinant human GrB $24 \mathrm{~h}$.

$100 \mathrm{nM}$ purified and recombinant human GrB

cleaved vitronectin in coated plates after $24 \mathrm{~h}$

$100 \mathrm{nM}$ purified and recombinant human GrB cleaved human fibronectin in coated plates after $24 \mathrm{~h} .{ }^{61} 100 \mathrm{nM}$ purified human GrB cleaved human fibronectin from ECM synthesized by cultured human coronary artery SMC after $24 \mathrm{~h}$ exposure. ${ }^{35}$ Human VWF coated on plate was cleaved by 50 and $100 \mathrm{nM}$ recombinant human GrB after $1 \mathrm{~h}$. GrB cleavage has similar efficiency to ADAMTS-13 cleavage of VWF.

Human fibrinogen coated on plate was

cleaved by $10-100 \mathrm{nM}$ recombinant human GrB after $1 \mathrm{~h}$. 
Table 2 (Continued)

\begin{tabular}{|c|c|c|c|}
\hline Substrates & $\begin{array}{l}\text { Potential physiological relevance/pathological } \\
\text { significance }\end{array}$ & Comments & Reference \\
\hline Plasminogen & $\begin{array}{l}\text { Cleavage produces the antiangiogenic protein } \\
\text { angiostatin, implications in angiogenesis. }\end{array}$ & $\begin{array}{l}3 \mu \mathrm{M} \text { recombinant human GrB cleaved human } \\
\text { plasminogen from plasma and purified human } \\
\text { plasminogen, producing } 50-54 \text { and } 29-38 \mathrm{kDa} \\
\text { fragments after } 4 \text { and } 16 \mathrm{~h} \text {. }\end{array}$ & 63 \\
\hline Plasmin & $\begin{array}{l}\text { Cleavage of plasmin may have an inhibitory effect } \\
\text { on angiogenesis. }\end{array}$ & $\begin{array}{l}3 \mu \mathrm{M} \text { recombinant human } \mathrm{GrB} \text { cleaved human } \\
\text { plasmin after } 16 \mathrm{~h} \text { into multiple fragments including } \\
25 \mathrm{kDa} \text { angiostatin. }\end{array}$ & 63 \\
\hline $\begin{array}{l}\text { T-cell glutamate } \\
\text { receptor }\end{array}$ & $\begin{array}{l}\text { Autoimmunity - GluR3B autoantigen synthesis. } \\
\text { Downregulation of receptor. Cleavage prevents } \\
\text { glutamate-induced adhesion to laminin, implications } \\
\text { in epilepsy }\end{array}$ & $\begin{array}{l}\text { Granule contents including GrB from activated T } \\
\text { cells cleaved GluR3, which was partially inhibited by } \\
\text { specific GrB inhibitors }\end{array}$ & 64 \\
\hline $\begin{array}{l}\text { Neuronal } \\
\text { glutamate } \\
\text { receptor }\end{array}$ & $\begin{array}{l}\text { Autoimmunity - receptor cleavage generates } \\
\text { GluR3B autoantigen when GluR3-GB recognition } \\
\text { sequence is not glycosylated. Implications in } \\
\text { Rasmussen's encephalitis. Cleavage site identified: } \\
\mathrm{D}^{388} \text {. }\end{array}$ & $\begin{array}{l}100 \mathrm{nM} \text { human } \mathrm{GrB} \text { cleaved the receptor from } \\
\text { murine cortical neuronal and hippocampal cell } \\
\text { lysates after } 1 \mathrm{~h} \text {. }\end{array}$ & 65 \\
\hline $\begin{array}{l}\text { Acetylcholine } \\
\text { receptor }\end{array}$ & $\begin{array}{l}\text { Autoimmunity - cleavage of the epsilon subunit may } \\
\text { produce a potential autoantigen in myasthenia } \\
\text { gravis. Cleavage site identified: } D^{195} \text {. }\end{array}$ & $\begin{array}{l}56-100 \mathrm{nM} \text { human } \mathrm{GrB} \text { was used to cleave the } \\
\text { human acetylcholine receptor. } \\
\text { Catalytic rate for GrB cleavage of } \alpha \text { and } \varepsilon \text { subunits } \\
\text { was determined as } 0.4 \times 10^{3} \text { and } 1.2 \times 10^{3} \mathrm{M}^{-1} \mathrm{~s}^{-1} \text {, } \\
\text { respectively. }\end{array}$ & 66 \\
\hline $\begin{array}{l}\text { Smooth muscle } \\
\text { cell matrix }\end{array}$ & $\begin{array}{l}\text { Implications in cell adhesion and anoikis. Relevance } \\
\text { to cardiovascular diseases such as atherosclerosis } \\
\text { and aneurysm. }\end{array}$ & $\begin{array}{l}100 \mathrm{nM} \text { purified human GrB generated multiple } \\
\text { fragments from ECM synthesized by cultured } \\
\text { human coronary artery SMC after } 24 \mathrm{~h} \text { exposure. }\end{array}$ & 35 \\
\hline
\end{tabular}

Gr, granzyme; ECM, extracellular matrix; SMC, smooth muscle cell; KO, knockout; NK, natural killer; RGD, Arg-Gly-Asp.

Extracellular roles for $\mathrm{GrH}, \mathrm{K}$, and $\mathrm{M}$ remain unknown at present. Although the possibility remains that these granzymes are exclusively intracellular, under certain conditions they also accumulate in the extracellular milieu. Soluble GrK is detected in the plasma of healthy individuals and its levels are found elevated in sepsis patients. ${ }^{68,69}$ Increased levels of circulating GrK are also associated with dengue fever. ${ }^{68}$

In atherosclerosis, elevated GrB plasma levels are detected in patients with acute coronary syndromes ${ }^{38}$ whereas GrB plasma levels are significantly higher in patients with unstable carotid plaques compared with those with stable lesions, and correspond to an increased incidence of cerebrovascular events. ${ }^{39}$ These studies suggest that extracellular GrB activity contributes to ECM degradation and promotes plaque instability and rupture. However, due to the lack of mouse models of plaque rupture, this hypothesis is yet to be directly tested in vivo.

Until recently, the major limitation of the extracellular granzyme hypothesis was the lack of in vivo evidence showing a definitive cause-effect relationship. In general, animal studies investigating the role of granzymes in disease have not assessed or attempted to differentiate between intracellular versus extracellular granzyme activity. In the first example of a perforin-independent, extracellular role for granzymes in any disease model, Chamberlain et al. ${ }^{60}$ have recently shown a perforin-independent role for $\mathrm{GrB}$ in the pathogenesis of abdominal aortic aneurysm (AAA) in vivo (Figure 2). AAA is a common, asymptomatic age-related disease characterized by immune-mediated apoptosis and ECM degradation and remodeling resulting in the deterioration and rupture of the arterial wall. ${ }^{70}$ Using an established mouse model of AAA in combination with perforin- and GrBdeficient mice, we were able to show, for the first time, that extracellular GrB activity can contribute to disease independently of perforin. In this study, GrB-deficient mice exhibited significantly less mortality due to aneurysm rupture whereas perforin deficiency exhibited no protective effect. Although no GrB was evident in healthy aortas, GrB colocalized to mast cells and macrophages infiltrating the media and adventitia of the aneurismal aorta wall as well as in macrophages and trapped lymphocytes in the intraluminal thrombus adjacent to the aneurysm in both mouse and human aneurysm samples. In addition, in vitro and in vivo analyses identified a novel extracellular GrB substrate, fibrillin-1, as one potential target for $\mathrm{GrB}$ in this disease. Fibrillin-1 associates with elastin in the aorta to form concentric elastic lamellae in the media that confer elasticity to the vessel. In addition, fibrillin-rich microfibrils exert their effects to stabilize the vessel wall by connecting lamellar rings to one another, to SMC, and to the subendothelial basement membrane. Along with collagen, fibrillin-1 microfibrils in the adventitia provide load-bearing support for the vessel. Cleavage of this protein results in a loss of elasticity, and in the case of aneurysms, augments vessel wall weakness and rupture (Figure 2). Although fibrillin-1 cleavage and disruption of the elastic lamellae were observed in angiotensin II-treated apolipoprotein $\mathrm{E}$ (apoE)-KO (positive AAA control) and angiotensin II-treated perforin/apoE-DKO, fibrillin-1 cleavage was prevented and vascular integrity was maintained in angiotensin II-treated GrB/apoE-DKO mice. ${ }^{60}$ Given these findings and the fact that GrB-KO and perforin-KO mice are readily available, determining whether a perforin-independent role for granzymes exists in other conditions is feasible and essential for expanding our understanding of extracellular granzyme activity and its contribution to degenerative disease pathogenesis. 


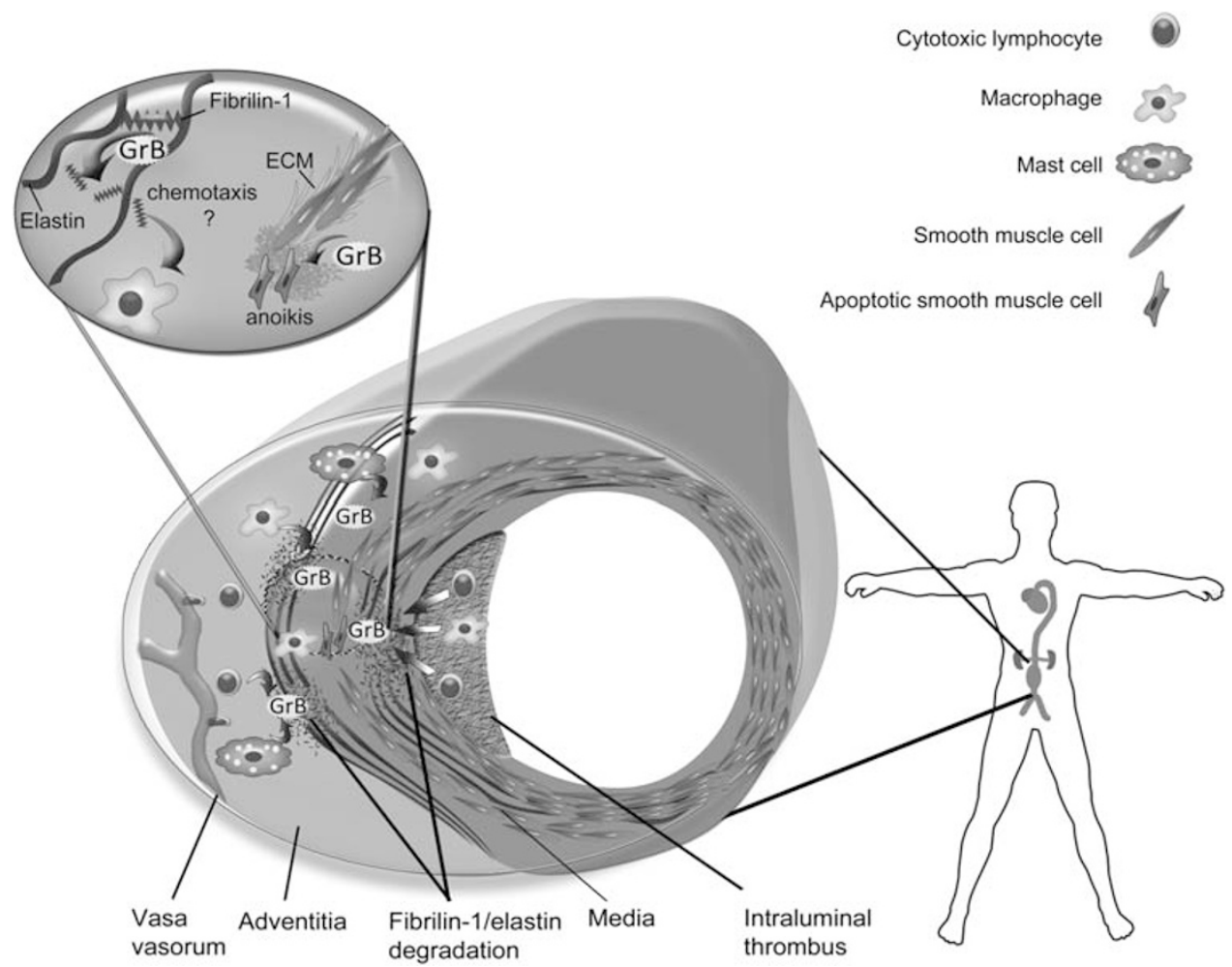

Figure 2 Extracellular, perforin-independent activity of granzyme B in aortic aneurysm. GrB-expressing lymphocytes, macrophages, and mast cells accumulate in the intraluminal thrombus, media, and adventitia. Extracellular GrB cleaves fibrillin-1, a key scaffolding ECM protein responsible for maintaining elastin fiber integrity. Fibrillin-1 fragments may also function as chemotactic agents, promoting immune cell infiltration in the media. GrB may cleave ECM leading to SMC detachment and subsequent anoikis. GrB proteolysis of ECM may contribute to weakening of the media and adventitia resulting in dilatation of the vessel wall and aneurysm

Extracellular granzyme activity has been suggested for COPD with patients exhibiting elevated soluble GrB in the BAL compared with healthy controls. ${ }^{14}$ Identified substrates for $\mathrm{GrA}$ and $\mathrm{GrB}$ are components of the alveolar ECM, such as collagen IV, fibronectin, and laminin, suggesting these granzymes may contribute extracellularly to alveolar wall damage in COPD (Figure 1). Recently, GrK levels were shown to be elevated in the BAL of patients with acute bronchopneumonia and in allergic asthma patients after allergen challenge treatment, however similar levels of GrK were observed between COPD and control patients. ${ }^{71}$ As GrB and possibly GrA are elevated in COPD, this study suggests that chronic inflammation does not equate to a pan-granzyme effect and that there may be inter-granzyme variability regarding activity and levels in different diseases.

Importantly, elevated granzyme levels in bodily fluids can arise simply as a consequence of localized tissue inflammation and thus more evidence showing direct extracellular involvement of granzymes in disease pathogenesis is required. Nevertheless, the aforementioned observations put forward some promising evidence of extracellular granzyme activity in aging and disease and leave the door open for future studies to validate the proposed actions using in vivo models.

\section{Granzyme-Induced Cytokine Release}

Recent studies suggest that granzymes participate in the modulation of cytokine expression and release in a variety of cell types thereby exacerbating the immune response and potentially contributing to a positive feedback loop that could augment granzyme production and release (Figure 3). With recent reports suggesting that GrA is not cytotoxic under physiological conditions, ${ }^{11}$ it appears that regulation of cytokine expression may be a central function of GrA in modulating the immune response.

The first evidence suggesting that GrA can influence cytokine activity came over a decade ago when Irmler et al. $^{72}$ found that GrA can function as an IL-1 $\beta$-converting enzyme. The authors showed that GrA, but not GrB, cleaves the $31 \mathrm{kDa}$ precursor form (plL-1 $\beta$ ) into the active $17 \mathrm{kDa}$ cytokine in cultured macrophages expressing plL-1 $\beta$. However, the mechanisms underlying GrA-induced cytokine release remain poorly understood. GrA-mediated ECM cleavage and disruption of the microtubule network was suggested to induce IL-8 release from cultured alveolar epithelial cell line, A549, in vitro. ${ }^{73}$ GrA induced IL-8 expression in lung, skin, and intestinal fibroblasts whereas IL-6 expression in both lung and intestinal fibroblasts is also induced by $\mathrm{GrA}^{73}$ The mechanism through which GrA mediates this process is unknown; however, the presence of a GrA-sensitive receptor on the surface of these cells is possible. The serine protease thrombin can induce IL-6 production in human lung fibroblasts through cleavage of the G-protein-coupled thrombin receptor (ThR) ${ }^{74}$ Although it was hypothesized that GrA might induce cytokine production by cleavage of this receptor, Sower et al. ${ }^{75}$ have shown that GrA is unable to activate the cloned receptor when transfected 




Figure 3 Proposed mechanism for granzyme activity in aging and chronic inflammation. Age-associated ROS production is accompanied by an increase in proinflammatory mediators resulting in immune cell recruitment to the effected tissue. ROS and other factors may induce both immune and nonimmune cells to produce and/or release granzymes. Granzymes exhibit the potential to initiate both cytotoxic and noncytotoxic events that promote tissue damage through the induction of apoptosis/anoikis, autoantigen production, cellular receptor cleavage and ECM degradation. Granzymes may augment the inflammatory process directly by inducing cytokine release and/or indirectly through the generation of chemotactic ECM cleavage fragments such as fibronectin fragments. This may facilitate a positive-feedback mechanism whereby granzyme activity further exacerbates immune cell infiltration resulting in more granzyme expression and release and a further progression of tissue damage leading to organ impairment

into insect cells, suggesting an alternative mechanism for GrA-induced cytokine release. An intracellular mechanism of GrA-induced cytokine expression in circulating monocytes has been proposed by Metkar et al. ${ }^{11}$ Using both human and mouse GrA, the authors show that IL-1 $\beta$, IL-6, IL-8, and TNF- $\alpha$ are produced in adherent PBMC in response to GrA. Cytokine expression was augmented when GrA was delivered internally to cells and the effect was shown to be partially dependent on caspase-1 activity. ${ }^{11}$

Although the induction of cytokines by GrA may have important implications in inflammatory disease pathogenesis, direct evidence linking these processes requires further investigation. Nevertheless, GrA-inducible cytokines have been linked to a variety of diseases. IL-1 $\beta$, a proinflammatory cytokine, is a major inducer of COX-2 in the central nervous system and is thought to contribute to inflammatory pain hypersensitivity. ${ }^{76}$ IL- 6 and TNF- $\alpha$ have been implicated in the onset and progression of a number of chronic inflammatory diseases (reviewed in Jones et al. ${ }^{77}$ and Muller-Ladner et $a .^{78}$ ) whereas IL-8 can also function as a proinflammatory cytokine, attracting circulating neutrophils to the interstitium. GrA-induced cytokine release offers an alternative to the traditionally proposed cytotoxic role for GrA in chronic inflammation. Future studies are warranted to determine additional cytokines and cell types that might be affected by granzymes and to further characterize the mechanisms involved.

Receptor Cleavage by the Granzymes. Granzymemediated cleavage of cellular receptors remains a potential mechanism by which granzyme activity may influence disease. The cleavage of cell membrane receptors by intracellular and extracellular proteases such as caspases and matrix metalloproteinases has been well described. ${ }^{79,80}$ Many of the trends and inferences established by these proteases in receptor cleavage may also hold true for granzymes.

As granzymes are localized both intracellularly and extracellularly, they possess the potential to cleave receptors on both sides of the membrane. Although several receptors have been identified as substrates for the granzymes, little is known regarding the functional consequences of granzyme-dependent receptor cleavage and the implications in inflammation and disease. In general, cleavage may result in receptor activation, signaling induction, promotion of apoptosis, and other cellular processes. Cleavage of cell receptors in chronic inflammation likely occurs due to either a specific or a nonspecific granzyme release during cellular degranulation. However, in the case of two of the granzyme receptor substrates, GluR3 receptor and the T-cell receptor, selfderived granzyme from cytotoxic cells may have an autocrine effect (discussed below). ${ }^{64,81}$ Also, with increasing literature emerging on nonimmune cell expression of granzymes, release of these proteases may have autocrine and paracrine effects on receptors in the absence of cytotoxic cells.

The cleavage of receptors by granzymes may activate receptors and promote inflammation in disease. The proteinase-activated receptor-2 (PAR-2), is a G-protein-coupled receptor which is activated by serine proteases such as trypsin and GrA, through the cleavage of the receptor's extracellular N-terminal domain, yielding the PAR-2-activating sequence SLIGRL (Table 2). ${ }^{49}$ Cleavage of this receptor may have proinflammatory effects as PAR- 2 activation can induce the expression of proinflammatory cytokines such as IL-8 and granulocyte macrophage-colony-stimulating factor in cultured keratinocytes in vitro. ${ }^{82,83}$

Several studies have reported conflicting evidence regarding the ability of GrA to cleave the ThR. Although ThR is a substrate for GrA in vitro, the in vivo relevance of this cleavage is less clear (Table 2). The $K_{\text {cat }} / K_{\mathrm{m}}$ for GrA is 1000 times lower than that of thrombin, suggesting that GrA is unlikely to be an effective ThR protease. ${ }^{50}$ It remains to be determined whether local concentrations of GrA released from cytotoxic granules by immune cells will be high enough to sufficiently cleave the receptor in vivo given its low catalytic efficiency in vitro. ${ }^{50}$

Although GrA cleaves the N-terminal portion of ThR in vitro at the thrombin cleavage site (Leu-Asp-Pro-Arg ${ }^{42}$ Ser), it failed to induce ThR-mediated calcium mobilization and activation of platelets, suggesting it may not have direct functional consequences on platelets in vivo. ${ }^{50,52,75}$ Interestingly, although GrA did not induce platelet aggregation, it attenuated thrombin-induced aggregation. ${ }^{52}$ This could suggest that GrA is competing with thrombin for ThR binding and thereby indirectly attenuating thrombin-mediated proteolysis of the receptor.

Although the functional consequences of GrA interaction with platelet ThR are controversial, neuronal ThR cleavage by GrA resulted in activation of the receptor on neuronal cells and astrocytes. Thus, cleavage of the ThR may be cell type dependent. ${ }^{51}$ GrA treatment resulted in complete and immediate neurite retraction and reversal of astrocyte 
stellation, in a ThR-dependent manner, suggesting that GrA may be involved in nervous system disorders such as allergic encephalomyelitis. ${ }^{51}$

Several receptors identified as substrates for granzymes are implicated in diseases of the nervous system. In addition to the suggested GrA-mediated cleavage of the ThR in neurite retraction, GrB cleaves the neuronal glutamate receptor (GluR3), the acetylcholine receptor (AChR), and the Sjögren's syndrome autoantigen, the type 3 muscarinic acetylcholine receptor. ${ }^{65,66,84}$ Although these receptors are implicated in neuronal autoimmunity, the functional consequences of $\mathrm{GrB}$ cleavage on receptor activation/signaling have not been fully examined. For example, the AChR is present at neuromuscular junctions and is reduced in these areas in myasthenia gravis, however whether GrB-mediated cleavage is responsible for this event is unknown (Table 2). ${ }^{66}$ Potential implication for GluR3 cleavage by $\mathrm{GrB}$ is also evident in CTLs. The autocrine release of GrB by these cells results in cleavage of the GluR3 receptor off of the cells. ${ }^{64}$ Cleavage of GluR3 resulted in a loss of glutamate-induced adhesion to laminin by $T$ cells, and may have implications in the neurotransmitter glutamate-mediated cross talk between $\mathrm{T}$ cells and nerves in autoimmunity and neurological disorders. ${ }^{64}$

This inherent granzyme activity on T-cell receptors may also hold true for the T-cell receptor- $\zeta$ chain. GrB has been shown to cleave this chain of the $\mathrm{T}$-cell receptor intracellularly. ${ }^{81}$ This receptor chain is necessary for T-cell activation, including survival and proliferation signals, and loss of the receptor has been linked to T-cell dysfunction. ${ }^{81}$

The cleavage of receptors by GrB may serve as an additional mechanism of inducing apoptosis. Fibroblast growth factor receptor-1 (FGFR) is an intracellular substrate for $\mathrm{GrB}$ and cleavage of this receptor promotes apoptosis. ${ }^{85}$ Although FGFR is cleaved intracellularly, GrB-mediated proteolysis separates the kinase portion of the receptor from the extracellular ligand-binding domain, disrupting signaling through this receptor. In addition, the $\mathrm{N}$-terminal cleavage fragment was shown to induce apoptosis in prostate cancer cells, suggesting a new potential pathway of indirect GrB-induced apoptosis through generation of proapoptotic receptor fragments. ${ }^{85}$ This suggests that even if a receptor is cleaved intracellularly, it may also have consequences extracellularly that subsequently alter its function.

The study of granzymes and receptor cleavage is in the early stages and how receptor cleavage influences inflammation and disease remains to be determined. Nearly all of the studies in this area to date are in vitro, many with soluble recombinant proteins containing only portions of the full receptor. Still, the potential implications of this work are substantial, and provide a framework for future studies.

\section{Conclusion}

Chronic inflammation is a central element of age-related cardiopulmonary disease. Oxidative stress and increased inflammatory mediators foster the release of effector molecules including granzymes that can promote local tissue damage by inducing cell death, inflammation and/or by cleaving extracellular substrates. Granzyme activity may promote the generation of proinflammatory cytokines, ECM fragments, and autoantigens that may further exacerbate the inflammatory response, giving rise to increased immune recruitment and elevated granzyme expression (Figure 3). Thus, granzymes may be key effector molecules that serve as pivotal agents in promoting a positive feedback cycle that may be common to many age-related chronic inflammatory disorders.

Evidence to date relating granzyme activity to chronic disease pathogenesis is promising yet in its infancy. Progression in this field will rely on the application of translational research approaches that incorporate what is known about where granzymes are found to be elevated clinically and incorporating animal studies and in vitro approaches to delineate mechanism. As the mice are available, approaches using a combination of granzyme- and perforin-deficient mice will be essential for elucidating the intracellular versus extracellular pathways. Likewise, as the extracellular pathway is revealed, it will be necessary to have access to specific granzyme inhibitors for injection to further delineate the extracellular role of granzymes in disease. As shown recently by Chamberlain et al., ${ }^{60}$ it is essential that both perforin-KO and granzyme-KO mice are used to distinguish the intracellular (perforin-dependent) and extracellular (perforin-independent) contributions of granzymes in disease models. As many studies in the past have used perforin-KO mice exclusively to rule out a role for granzymes in murine disease models, many of these studies may be worth revisiting, as they may have inadvertently excluded the extracellular contribution of granzymes.

\section{Conflict of interest}

DJG is a Founder and consultant for viDA Therapeutics, Inc.

Acknowledgements. We acknowledge funding from the Canadian Institutes of Health Research (CIHR) (DJG), Michael Smith Foundation for Health Research (MSFHR)/British Columbia Transplant Research Foundation (DJG), and the Heart and Stroke Foundation (HSFC) (DJG). WAB was supported by an Alexander Graham Bell Canadian Graduate Studentship from the Natural Sciences and Engineering Research Council of Canada and a graduate fellowship from the MSFHR. AH is grateful for the support from CIHR Canada Graduate Scholarship Master's Award. PRH was supported by CIHR Skin Research Training Centre. SJW is a recipient of a CIHR Fellowship award and a CIHR-IMPACT Strategic Training postdoctoral fellowship.

1. Libby P. Inflammatory mechanisms: the molecular basis of inflammation and disease Nutr Rev 2007; 65 (12 Part 2): S140-S146.

2. Chung HY, Cesari M, Anton S, Marzetti E, Giovannini S, Seo AY et al. Molecular inflammation: underpinnings of aging and age-related diseases. Ageing Res Rev 2009; 8: $18-30$.

3. Brod SA. Unregulated inflammation shortens human functional longevity. Inflamm Res 2000; 49: 561-570.

4. Libby P. Inflammation in atherosclerosis. Nature 2002; 420: 868-874.

5. Pasceri V, Yeh ET. A tale of two diseases: atherosclerosis and rheumatoid arthritis. Circulation 1999; 100: 2124-2126.

6. Demedts IK, Demoor T, Bracke KR, Joos GF, Brusselle GG. Role of apoptosis in the pathogenesis of COPD and pulmonary emphysema. Respir Res 2006; 7: 53-63.

7. Gauldie J. Inflammation and the aging process: devil or angel. Nutr Rev 2007; 65 (12 Part 2): S167-S169.

8. Chowdhury D, Lieberman J. Death by a thousand cuts: granzyme pathways of programmed cell death. Annu Rev Immunol 2008; 26: 389-420.

9. Boivin WA, Cooper DM, Hiebert PR, Granville DJ. Intracellular versus extracellular granzyme B in immunity and disease: challenging the dogma. Lab Invest 2009; 89: 1195-1220. 
10. Pardo J, Aguilo J, Anel A, Martin P, Joeckel L, Borner C et al. The biology of cytotoxic cell granule exocytosis pathway: granzymes have evolved to induce cell death and inflammation. Microbes Infect 2009; 11: 452-459.

11. Metkar SS, Menaa C, Pardo J, Wang B, Wallich R, Freudenberg M et al. Human and mouse granzyme A induce a proinflammatory cytokine response. Immunity 2008; 29: 720-733.

12. Hogg JC, Timens W. The pathology of chronic obstructive pulmonary disease. Annu Rev Pathol 2009; 4: 435-459.

13. Ngan DA, Vickerman SV, Granville DJ, Man SF, Sin DD. The possible role of granzyme B in the pathogenesis of chronic obstructive pulmonary disease. Ther Adv Respir Dis 2009; 3 113-129.

14. Hodge S, Hodge G, Nairn J, Holmes M, Reynolds PN. Increased airway granzyme B and perforin in current and ex-smoking COPD subjects. COPD 2006; 3: 179-187.

15. Vernooy JH, Moller GM, van Suylen RJ, van Spijk MP, Cloots RH, Hoet PH et al. Increased granzyme A expression in type II pneumocytes of patients with severe chronic obstructive pulmonary disease. Am J Respir Crit Care Med 2007; 175: 464-472.

16. Choy JC, McDonald PC, Suarez AC, Hung VH, Wilson JE, McManus BM et al. Granzyme B in atherosclerosis and transplant vascular disease: association with cell death and atherosclerotic disease severity. Mod Pathol 2003; 16: 460-470.

17. Hernandez-Pigeon $\mathrm{H}$, Jean $\mathrm{C}$, Charruyer A, Haure MJ, Titeux M, Tonasso L et al. Human keratinocytes acquire cellular cytotoxicity under UV-B irradiation. Implication of granzyme B and perforin. J Biol Chem 2006; 281: 13525-13532.

18. Hernandez-Pigeon $\mathrm{H}$, Jean $\mathrm{C}$, Charruyer $\mathrm{A}$, Haure MJ, Baudouin $\mathrm{C}$, Charveron $\mathrm{M}$ et al. UVA induces granzyme $B$ in human keratinocytes through MIF: implication in extracellular matrix remodeling. J Biol Chem 2007; 282: 8157-8164.

19. Hirst CE, Buzza MS, Sutton VR, Trapani JA, Loveland KL, Bird PI. Perforin-independent expression of granzyme $B$ and proteinase inhibitor 9 in human testis and placenta suggests a role for granzyme B-mediated proteolysis in reproduction. Mol Hum Reprod 2001; 7 1133-1142.

20. Strik MC, de Koning PJ, Kleijmeer MJ, Bladergroen BA, Wolbink AM, Griffith JM et al. Human mast cells produce and release the cytotoxic lymphocyte associated protease granzyme B upon activation. Mol Immunol 2007; 44: 3462-3472.

21. Sasson R, Dantes A, Tajima K, Amsterdam A. Novel genes modulated by FSH in norma and immortalized FSH-responsive cells: new insights into the mechanism of FSH action. FASEB J 2003; 17: 1256-1266.

22. Hagn M, Schwesinger E, Ebel V, Sontheimer K, Maier J, Beyer T et al. Human B cells secrete granzyme $\mathrm{B}$ when recognizing viral antigens in the context of the acute phase cytokine IL-21. J Immunol 2009; 183: 1838-1845.

23. Tschopp CM, Spiegl N, Didichenko S, Lutmann W, Julius P, Virchow JC et al. Granzyme B, a novel mediator of allergic inflammation: its induction and release in blood basophils and human asthma. Blood 2006; 108: 2290-2299.

24. Rissoan MC, Duhen T, Bridon JM, Bendriss-Vermare N, Peronne C, de Saint Vis B et al. Subtractive hybridization reveals the expression of immunoglobulin-like transcript 7 Eph-B1, granzyme B, and 3 novel transcripts in human plasmacytoid dendritic cells. Blood 2002; 100: 3295-3303.

25. Horiuchi K, Saito S, Sasaki R, Tomatsu T, Toyama $Y$. Expression of granzyme B in human articular chondrocytes. J Rheumatol 2003; 30: 1799-1810.

26. Hu SX, Wang S, Wang JP, Mills GB, Zhou Y, Xu HJ. Expression of endogenous granzyme $B$ in a subset of human primary breast carcinomas. Br J Cancer 2003; 89: 135-139.

27. Gondek DC, Lu LF, Quezada SA, Sakaguchi S, Noelle RJ. Cutting edge: contact-mediated suppression by $\mathrm{CD} 4+\mathrm{CD} 25+$ regulatory cells involves a granzyme B-dependent, perforinindependent mechanism. J Immunol 2005; 174: 1783-1786.

28. Grossman WJ, Verbsky JW, Tollefsen BL, Kemper C, Atkinson JP, Ley TJ. Differentia expression of granzymes $A$ and $B$ in human cytotoxic lymphocyte subsets and $T$ regulatory cells. Blood 2004; 104: 2840-2848.

29. Kim WJ, Kim H, Suk K, Lee WH. Macrophages express granzyme B in the lesion areas of atherosclerosis and rheumatoid arthritis. Immunol Lett 2007: 111: 57-65.

30. Hansson GK. Inflammation, atherosclerosis, and coronary artery disease. N Engl J Med 2005; 352: 1685-1695

31. Chamberlain CM, Granville DJ. The role of Granzyme B in atheromatous diseases. Can J Physiol Pharmacol 2007; 85: 89-95.

32. Napoli C, Ignarro LJ. Nitric oxide and pathogenic mechanisms involved in the development of vascular diseases. Arch Pharm Res 2009; 32: 1103-1108.

33. Ferlito M, Irani K, Faraday N, Lowenstein CJ. Nitric oxide inhibits exocytosis of cytolytic granules from lymphokine-activated killer cells. Proc Natl Acad Sci USA 2006; 103: 1168911694

34. Young JL, Sukhova GK, Foster D, Kisiel W, Libby P, Schonbeck U. The serpin proteinase inhibitor 9 is an endogenous inhibitor of interleukin 1beta-converting enzyme (caspase-1) activity in human vascular smooth muscle cells. J Exp Med 2000; 191: 1535-1544.

35. Choy JC, Hung VH, Hunter AL, Cheung PK, Motyka B, Goping IS et al. Granzyme B induces smooth muscle cell apoptosis in the absence of perforin: involvement of extracellular matrix degradation. Arterioscler Thromb Vasc Biol 2004; 24: 2245-2250.

36. Choy JC, Cruz RP, Keriner A, Geisbrecht J, Sawchuk T, Fraser SA et al. Granzyme B induces endothelial cell apoptosis and contributes to the development of transplant vascular disease. Am J Transplant 2005; 5: 494-499.

37. Tsuru R, Kondo H, Hojo Y, Gama M, Mizuno O, Katsuki T et al. Increased granzyme B production from peripheral blood mononuclear cells in patients with acute coronary syndrome. Heart 2008; 94: 305-310.
38. Kondo $\mathrm{H}$, Hojo $\mathrm{Y}$, Tsuru R, Nishimura $\mathrm{Y}$, Shimizu $\mathrm{H}$, Takahashi $\mathrm{N}$ et al. Elevation of plasma granzyme B levels after acute myocardial infarction. Circ J 2009; 73: 503-507.

39. Skjelland M, Michelsen AE, Krohg-Sorensen K, Tennoe B, Dahl A, Bakke S et al. Plasma levels of granzyme $B$ are increased in patients with lipid-rich carotid plaques as determined by echogenicity. Atherosclerosis 2007; 195: e142-e146.

40. Schiller NK, Boisvert WA, Curtiss LK. Inflammation in atherosclerosis: Iesion formation in LDL receptor-deficient mice with perforin and Lyst(beige) mutations. Arterioscler Thromb Vasc Biol 2002; 22: 1341-1346.

41. Kramer MD, Simon MM. Are proteinases functional molecules of lymphocytes-T. Immunol Today 1987; 8: 140-142.

42. Isaaz S, Baetz K, Olsen K, Podack E, Griffiths GM. Serial killing by cytotoxic T lymphocytes: $T$ cell receptor triggers degranulation, re-filling of the lytic granules and secretion of lytic proteins via a non-granule pathway. Eur J Immunol 1995; 25: 1071-1079.

43. Prakash MD, Bird CH, Bird PI. Active and zymogen forms of granzyme B are constitutively released from cytotoxic lymphocytes in the absence of target cell engagement. Immunol Cell Biol 2009; 87: 249-254.

44. Skold S, Zeberg L, Gullberg U, Olofsson T. Functional dissociation between proforms and mature forms of proteinase 3 , azurocidin, and granzyme $B$ in regulation of granulopoiesis. Exp Hematol 2002; 30: 689-696.

45. Takahashi $\mathrm{K}$, Nakamura $\mathrm{T}$, Adachi $\mathrm{H}$, Yagita $\mathrm{H}$, Okumura $\mathrm{K}$. Antigen-independen $T$ cell activation mediated by a very late activation antigen-like extracellular matrix receptor. Eur J Immunol 1991; 21: 1559-1562.

46. Doucey MA, Legler DF, Faroudi M, Boucheron N, Baumgaertner P, Naeher D et al. The beta1 and beta3 integrins promote $T$ cell receptor-mediated cytotoxic $T$ lymphocyte activation. J Biol Chem 2003; 278: 26983-26991.

47. Vacca A, Ria R, Presta M, Ribatti D, lurlaro M, Merchionne F et al. alpha(v)beta(3) integrin engagement modulates cell adhesion, proliferation, and protease secretion in human lymphoid tumor cells. Exp Hematol 2001; 29: 993-1003.

48. Ybarrondo B, O'Rourke AM, McCarthy JB, Mescher MF. Cytotoxic T-lymphocyte interaction with fibronectin and vitronectin: activated adhesion and cosignalling. Immunology 1997; 91: 186-192.

49. Hansen KK, Sherman PM, Cellars L, Andrade-Gordon P, Pan Z, Baruch A et al. A major role for proteolytic activity and proteinase-activated receptor-2 in the pathogenesis of infectious colitis. Proc Natl Acad Sci USA 2005; 102: 8363-8368.

50. Parry MA, Myles T, Tschopp J, Stone SR. Cleavage of the thrombin receptor: identification of potential activators and inactivators. Biochem J 1996; 320 (Part 1): 335-341.

51. Suidan HS, Bouvier J, Schaerer E, Stone SR, Monard D, Tschopp J. Granzyme A released upon stimulation of cytotoxic $T$ lymphocytes activates the thrombin receptor on neuronal cells and astrocytes. Proc Natl Acad Sci USA 1994; 91: 8112-8116.

52. Suidan HS, Clemetson KJ, Brown-Luedi M, Niclou SP, Clemetson JM, Tschopp J et al. The serine protease granzyme $A$ does not induce platelet aggregation but inhibits responses triggered by thrombin. Biochem J 1996; 315 (Part 3): 939-945.

53. Simon MM, Prester M, Nerz G, Kramer MD, Fruth U. Release of biologically active fragments from human plasma-fibronectin by murine T cell-specific proteinase 1 (TSP-1). Biol Chem Hoppe Seyler 1988; 369 (Suppl): 107-112.

54. Hirayasu H, Yoshikawa Y, Tsuzuki S, Fushiki T. A lymphocyte serine protease granzyme A causes detachment of a small-intestinal epithelial cell line (IEC-6). Biosci Biotechnol Biochem 2008; 72: 2294-2302.

55. Simon MM, Kramer MD, Prester M, Gay S. Mouse T-cell associated serine proteinase 1 degrades collagen type IV: a structural basis for the migration of lymphocytes through vascular basement membranes. Immunology 1991; 73: 117-119.

56. Brunner G, Simon MM, Kramer MD. Activation of pro-urokinase by the human T cellassociated serine proteinase HUTSP-1. FEBS Lett 1990; 260: 141-144.

57. Vanguri $P$, Lee $E$, Henkart $P$, Shin ML. Hydrolysis of myelin basic protein in myelin membranes by granzymes of large granular lymphocytes. J Immunol 1993; 150: 2431-2439.

58. Froelich CJ, Zhang X, Turbov J, Hudig D, Winkler U, Hanna WL. Human granzyme B degrades aggrecan proteoglycan in matrix synthesized by chondrocytes. J Immunol 1993; 151: 7161-7171.

59. Ronday HK, van der Laan WH, Tak PP, de Roos JA, Bank RA, TeKoppele JM et al. Human granzyme $B$ mediates cartilage proteoglycan degradation and is expressed at the invasive front of the synovium in rheumatoid arthritis. Rheumatology (Oxford) 2001; 40: 55-61.

60. Chamberlain C, Ang L, Boivin W, Cooper D, Williams S, Zhao H et al. Perforin-independent extracellular granzyme $\mathrm{B}$ activity contributes to abdominal aortic aneurysm. Am J Pathol 2010; 176: (in press).

61. Buzza MS, Zamurs L, Sun J, Bird CH, Smith Al, Trapani JA et al. Extracellular matrix remodeling by human granzyme $B$ via cleavage of vitronectin, fibronectin, and laminin. J Biol Chem 2005; 280: 23549-23558.

62. Buzza MS, Dyson JM, Choi H, Gardiner EE, Andrews RK, Kaiserman D et al. Antihemostatic activity of human granzyme $B$ mediated by cleavage of von Willebrand factor. J Biol Chem 2008; 283: 22498-22504.

63. Mulligan-Kehoe MJ, Drinane MC, Mollmark J, Casciola-Rosen L, Hummers LK, Hall A et al. Antiangiogenic plasma activity in patients with systemic sclerosis. Arthritis Rheum 2007; 56: 3448-3458.

64. Ganor Y, Teichberg VI, Levite M. TCR activation eliminates glutamate receptor GluR3 from the cell surface of normal human T cells, via an autocrine/paracrine granzyme B-mediated proteolytic cleavage. J Immunol 2007; 178: 683-692. 
65. Gahring L, Carlson NG, Meyer EL, Rogers SW. Granzyme B proteolysis of a neuronal glutamate receptor generates an autoantigen and is modulated by glycosylation. $\mathrm{J}$ Immunol 2001; 166: 1433-1438.

66. Casciola-Rosen L, Miagkov A, Nagaraju K, Askin F, Jacobson L, Rosen A et al. Granzyme $B$ : evidence for a role in the origin of myasthenia gravis. J Neuroimmunol 2008; 201-202: 33-40.

67. Vettel U, Brunner G, Bar-Shavit R, Vlodavsky I, Kramer MD. Charge-dependent binding of granzyme A (MTSP-1) to basement membranes. Eur J Immunol 1993; 23: 279-282.

68. Bade B, Lohrmann J, ten Brinke A, Wolbink AM, Wolbink GJ, ten Berge IJ et al. Detection of soluble human granzyme $\mathrm{K}$ in vitro and in vivo. Eur J Immunol 2005; 35: 2940-2948.

69. Rucevic M, Fast LD, Jay GD, Trespalcios FM, Sucov A, Siryaporn E et al. Altered levels and molecular forms of granzyme k in plasma from septic patients. Shock 2007; 27: 488-493.

70. Baxter BT, Terrin MC, Dalman RL. Medical management of small abdominal aortic aneurysms. Circulation 2008; 117: 1883-1889.

71. Bratke K, Klug A, Julius P, Kuepper M, Lommatzsch M, Sparmann G et al. Granzyme K: a novel mediator in acute airway inflammation. Thorax 2008; 63: 1006-1011.

72. Irmler M, Hertig S, MacDonald HR, Sadoul R, Becherer JD, Proudfoot A et al. Granzyme A is an interleukin 1 beta-converting enzyme. J Exp Med 1995; 181: 1917-1922.

73. Sower LE, Klimpel GR, Hanna W, Froelich CJ. Extracellular activities of human granzymes. I. Granzyme A induces IL6 and IL8 production in fibroblast and epithelial cell lines. Cell Immunol 1996; 171: 159-163.

74. Sower LE, Froelich CJ, Carney DH, Fenton II JW, Klimpel GR. Thrombin induces IL-6 production in fibroblasts and epithelial cells. Evidence for the involvement of the seventransmembrane domain (STD) receptor for alpha-thrombin. J Immunol 1995; 155: 895-901.

75. Sower LE, Froelich CJ, Allegretto N, Rose PM, Hanna WD, Klimpel GR. Extracellular activities of human granzyme A. Monocyte activation by granzyme A versus alphathrombin. J Immunol 1996; 156: 2585-2590.
76. Samad TA, Moore KA, Sapirstein A, Billet S, Allchorne A, Poole S et al. Interleukin-1betamediated induction of Cox-2 in the CNS contributes to inflammatory pain hypersensitivity Nature 2001; 410: 471-475.

77. Jones SA, Richards PJ, Scheller J, Rose-John S. IL-6 transsignaling: the in vivo consequences. J Interferon Cytokine Res 2005; 25: 241-253.

78. Muller-Ladner $U$, Alten $R$, Heiligenhaus A, Kekow J, Koletzko S, Mrowietz U et al. ['TRECID', TNFalpha related chronic inflammatory diseases - a new multiple diseases bridging concept]. Dtsch Med Wochenschr 2009; 134: 2132-2136.

79. Graf D, Bode JG, Haussinger D. Caspases and receptor cleavage. Arch Biochem Biophys 2007; 462: 162-170.

80. Chang C, Werb Z. The many faces of metalloproteases: cell growth, invasion, angiogenesis and metastasis. Trends Cell Biol 2001; 11: S37-S43.

81. Wieckowski E, Wang GQ, Gastman BR, Goldstein LA, Rabinowich H. Granzyme Bmediated degradation of T-cell receptor zeta chain. Cancer Res 2002; 62: 4884-4889.

82. Wakita H, Furukawa F, Takigawa M. Thrombin and trypsin induce granulocytemacrophage colony-stimulating factor and interleukin-6 gene expression in cultured normal human keratinocytes. Proc Assoc Am Physicians 1997; 109: 190-207.

83. Hou L, Kapas S, Cruchley AT, Macey MG, Harriott P, Chinni C et al. Immunolocalization of protease-activated receptor-2 in skin: receptor activation stimulates interleukin-8 secretion by keratinocytes in vitro. Immunology 1998; 94: 356-362.

84. Nagaraju K, Cox A, Casciola-Rosen L, Rosen A. Novel fragments of the Sjogren's syndrome autoantigens alpha-fodrin and type 3 muscarinic acetylcholine receptor generated during cytotoxic lymphocyte granule-induced cell death. Arthritis Rheum 2001; 44: 2376-2386.

85. Loeb CR, Harris JL, Craik CS. Granzyme B proteolyzes receptors important to proliferation and survival, tipping the balance toward apoptosis. J Biol Chem 2006; 281: 28326-28335. 